\title{
Interpretation of EC Fine Grid Numerical Prediction Products in the Forecast of Frozen Fog in Urumqi Airport
}

\author{
Hongru Yang1, Nan Wang1*, Yulin Qin², Dawei Fan'1 \\ ${ }^{1}$ Civil Aviation Xinjiang Air Traffic Control Bureau Meteorological Center, Urumqi, China \\ ${ }^{2}$ Jilin Province Observatory, Changchun, China \\ Email: *wangnan1986yang@163.com
}

How to cite this paper: Yang, H.R., Wang, N., Qin, Y.L. and Fan, D.W. (2018) Interpretation of EC Fine Grid Numerical Prediction Products in the Forecast of Frozen Fog in Urumqi Airport. Journal of Geoscience and Environment Protection, 6, $100-110$.

https://doi.org/10.4236/gep.2018.69008

Received: July 11, 2018

Accepted: September 7, 2018

Published: September 10, 2018

Copyright $\odot 2018$ by authors and Scientific Research Publishing Inc. This work is licensed under the Creative Commons Attribution International License (CC BY 4.0).

http://creativecommons.org/licenses/by/4.0/

\begin{abstract}
In this paper, Urumqi Airport time-lapse ground man-made observation data from November 2015 to February 2017, European fine grid $(0.25 \times 0.25)$ initial field (20 o'clock) and the forecast field within 24 hours were utilized. From November 2015 to February 2016, the relevant materials were used as research samples (a total of 948 times), and from November 2016 to February 2017 as test samples (a total of 922 times), statistical methods were used to establish the scoring standards. And each relevant element was scored. After the score, the score level range was delineated, and the visibility forecast was performed according to the scope. The conclusions are as follows: 1) European fine grid forecast products are with good correspondence with the visibility of this field are $850 \mathrm{hPa}$ and $2 \mathrm{~m}$ high temperature inversion, $850 \mathrm{hPa}$ relative humidity and $850 \mathrm{hPa}$ wind field over the field. 2) Through the statistical analysis of scores, it is defined that the score below 400 is level 4, the score above 1000 is level 1, the difference is significant, and the forecast indication is strong. Level 2 and level 3 are more evenly distributed, with no more concentrated fractions. 3) Applying the test sample to test the above indicators. The forecast accuracy of level 1 is $61.2 \%$, and the forecast accuracy of level 4 is $97.2 \%$, so level 1 and level 4 are expected to obtain better forecast results, which is of practical application value.
\end{abstract}

\section{Keywords}

Airport Freezing Fog, Forecast Product Release, Classification Prediction

\section{Introduction}

With the rapid development of China's aviation industry, large-scale delays in 
flights due to weather, air traffic control, airport security and passengers' own reasons are not uncommon. According to the Civil Aviation Administration's 2012 Civil Aviation Industry Development Statistics Bulletin [1], the normal rate of national flights for the year was only $74.8 \%$, of which $21.6 \%$ were due to bad weather. For Urumqi Airport, the cancellation of flight delay caused by low-visibility weather is more than the majority of all weather factors, especially the low-visibility weather caused by fog.

The forecasting methods for frozen fog are more diverse with the level of science and technology. In recent years, the level of numerical weather prediction at home and abroad has been continuously improved. In this environment, the number of numerical prediction products is increasing, and the precision of products is also increasing. More and more products have been used by a large number of meteorological business researchers and related departments, especially civil aviation meteorology, mostly concentrated in the research of numerical simulation analysis and parameterization scheme [2] [3] [4]. In this context, there are many numerical products that are constantly being produced, which have achieved good results in the weather forecasting business.

For the study of frozen fog at Urumqi Airport, Zhu Lei [5] analyzed the seasonal and interannual variations of frozen fog. It is proposed that the weather phenomenon causing low visibility of Urumqi Airport is foggy, smoke, and sand, and most of the low visibility is caused by freezing fog. Wang Nan and Yang Hongru [6] [7] analyzed the non-uniformity characteristics and the classification of frozen fog circulation in the fog season of Urumqi Airport, which provided a basis for forecasting the freezing fog weather. The research on airport fog has focused on the statistics of circulation types and the distribution characteristics of fog scales, and has achieved great results, providing reference for airport fog forecasting and on-time safe operation of flights. However, research on the application of numerical forecast product pairs for airport fog is still blank. In addition, with the global climate change, Urumqi airport fog performance in addition to different characteristics, changes in the law of production and elimination make the fog forecast more difficult to grasp. Therefore, the use of low-time-space density numerical forecasting products in the interpretation of heavy fog forecasting is far from meeting the rapid development of weather forecasting services.

At the same time, there is no numerical model at home and abroad that can directly output the forecast products of fog, which shows the complexity of visibility forecasting and the difficulty of improving the accuracy of forecasting. Therefore, it is extremely important to apply numerical prediction products with high spatial and temporal resolution to strengthen the research on the interpretation of fog prediction [8].

This paper attempts to extract the physical factors closely related to the visibility of the field through the interpretation of European fine mesh physical quantity products, find out the forecast indicators of Urumqi visibility, improve 
the accuracy of forecasting, and provide reference for the actual forecasting work.

\section{Materials and Methods}

\subsection{Data}

In this paper, Urumqi Airport time-lapse ground man-made observation data from November 2015 to February 2017, European fine grid $(0.25 \times 0.25)$ initial field (20 o'clock) and the forecast field within 24 hours were utilized. The relevant data from November 2015 to February 2016 was used as a sample of research (a total of 948 times), and from November 2016 to February 2017 as a test sample (a total of 922 times).

\subsection{Methods}

The appearance of the frozen fog requires a static and stable structure. The static and stable structure combined with the physical quantity shows the high altitude situation without obvious temperature advection, the ground form with poor air pressure, the inversion temperature, and the humidity near the ground. Therefore, this paper selects 7 physical quantities with close visibility and physical meaning, $500 \mathrm{hpa}$ height field/temperature field, $850 \mathrm{hPa}$ relative humidity, 850 hpa wind field, $850 \mathrm{hpa}$ temperature, T2m temperature, mean sea level pressure. (Note: $2 \mathrm{~m}$ relative humidity is highly concentrated in the total time between 70 - 95, there is almost no difference between the visibility of each level, so the physical quantity is not considered in this paper). Urumqi Diwopu International Airport (hereinafter referred to as the airport), the coordinates of the center point of the runway are $43^{\circ} 54^{\prime} 23^{\prime \prime} \mathrm{N}, 87^{\circ} 28^{\prime} 28^{\prime \prime} \mathrm{E}$. In this paper, $\left(44^{\circ} \mathrm{N}, 87.5^{\circ} \mathrm{E}\right)$ is used as the data of the airport to extract and determine the indicators of different visibility weather occurrence.

The generation of freezing fog is a very complicated process, and there is no exact relationship between it and each physical quantity. It is the embodiment of the final effect after the interaction of multiple physical quantities with the law of the airport itself and the upstream and downstream effects. Therefore, this paper divides the visibility of the field into four levels for research and forecasting, and in order to distinguish between level 1 and level 4, the basic scores of the above two are significantly different. See Table 1 for details.

\section{Physical Quantity Field Analysis and Evaluation Score}

\subsection{Relationship between Visibility and 500 hpa Circulation and Sea Level Pressure Field}

For the discrimination of the circulation background, the "Yes" and "No" discriminant, combined with the previous research conclusions, define the westward airflow type, the weak warm ridge type, the Bahu trough type, and the middle Asian high pressure ridge type as the circulation form of the occurrence of heavy fog. As shown in Figure 1. 

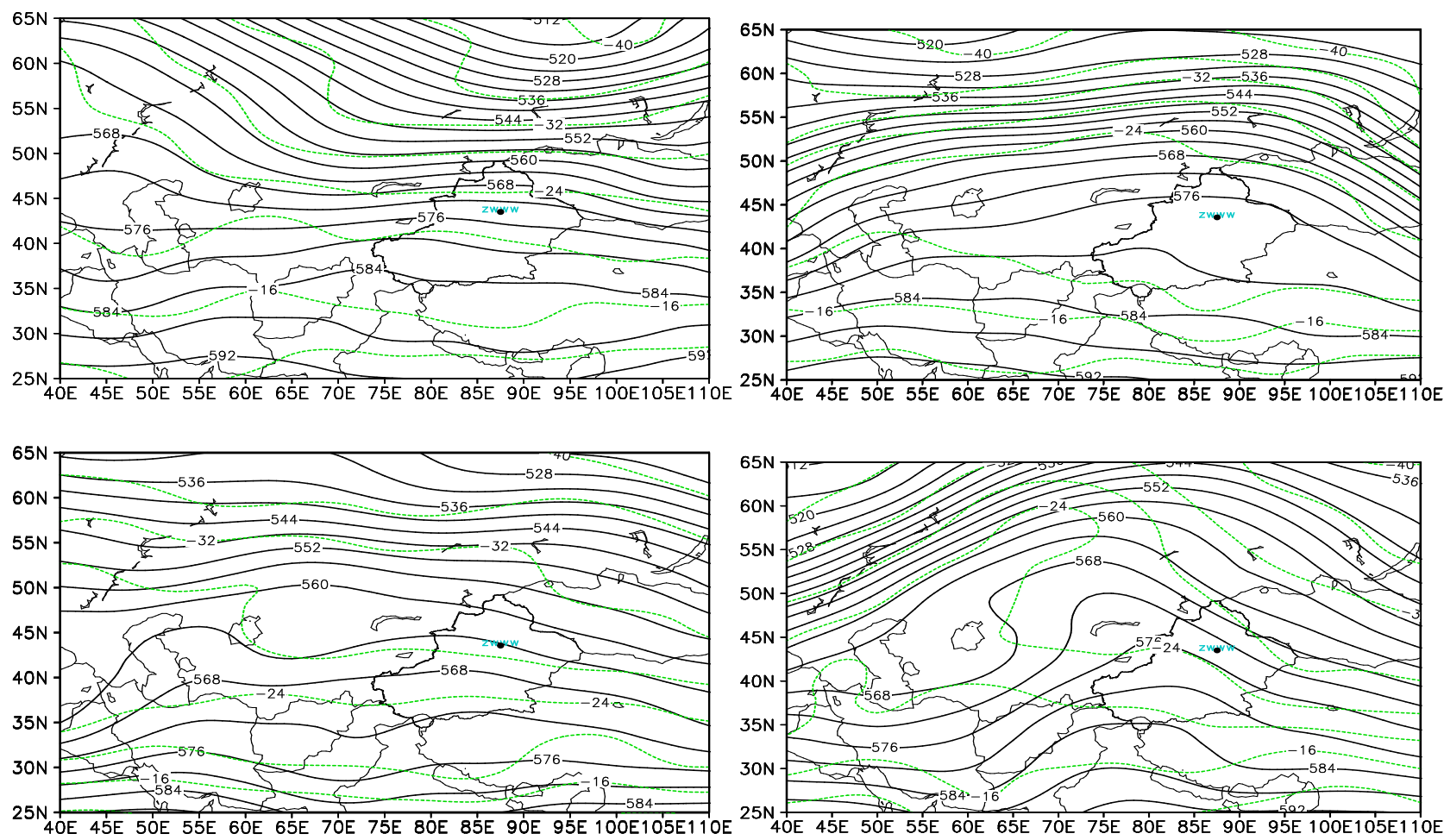

Figure 1. 500 hpa circulation form of frozen fog.

Table 1. Division of visibility levels.

\begin{tabular}{cccc}
\hline Levels & Visibility Range & Base Score & Influence Level \\
\hline 4 & $>3000 \mathrm{~m}$ & 0 & Can Flight \\
3 & $1000-3000 \mathrm{~m}$ & 40 & Monitoring Phase \\
2 & $500-1000 \mathrm{~m}$ & 100 & Monitoring Phase \\
1 & $\leq 500 \mathrm{~m}$ & 500 & Not Flight \\
\hline
\end{tabular}

These figures are derived from the European fine grid $(0.25 * 0.25)$ initial field (20 o'clock) and the forecast field within 24 hours. According to experience, the ground form is divided into the bottom of the high-pressure periphery or the bottom of the bottom, the belt-shaped high-pressure type, the transition zone of the north high and the low south, and the east-high west low-type is the form of the pressure field of the fog, as shown in Figure 2.

In addition, quantitative indicators can also be used to analyze: According to the relevant conclusions, based on the Lamb-Jenkinson method, it is concluded that there are five types of circulation in the field of heavy fog [9]. They are cyclone type (15.35\%), easterly airflow type $(13.17 \%)$, southeast airflow type (13.0\%), westward airflow type (12.24\%), and anticyclonic type (11.08\%). And the sum of the probability of appealing the five types of circulation types is $64.85 \%$, in order to judge the sea level pressure field of the fog. The above judgment is divided into "Yes" or "No", and based on the "Yes" discriminant, combined with the following factor scores, the weather conditions of the field are predicted. 

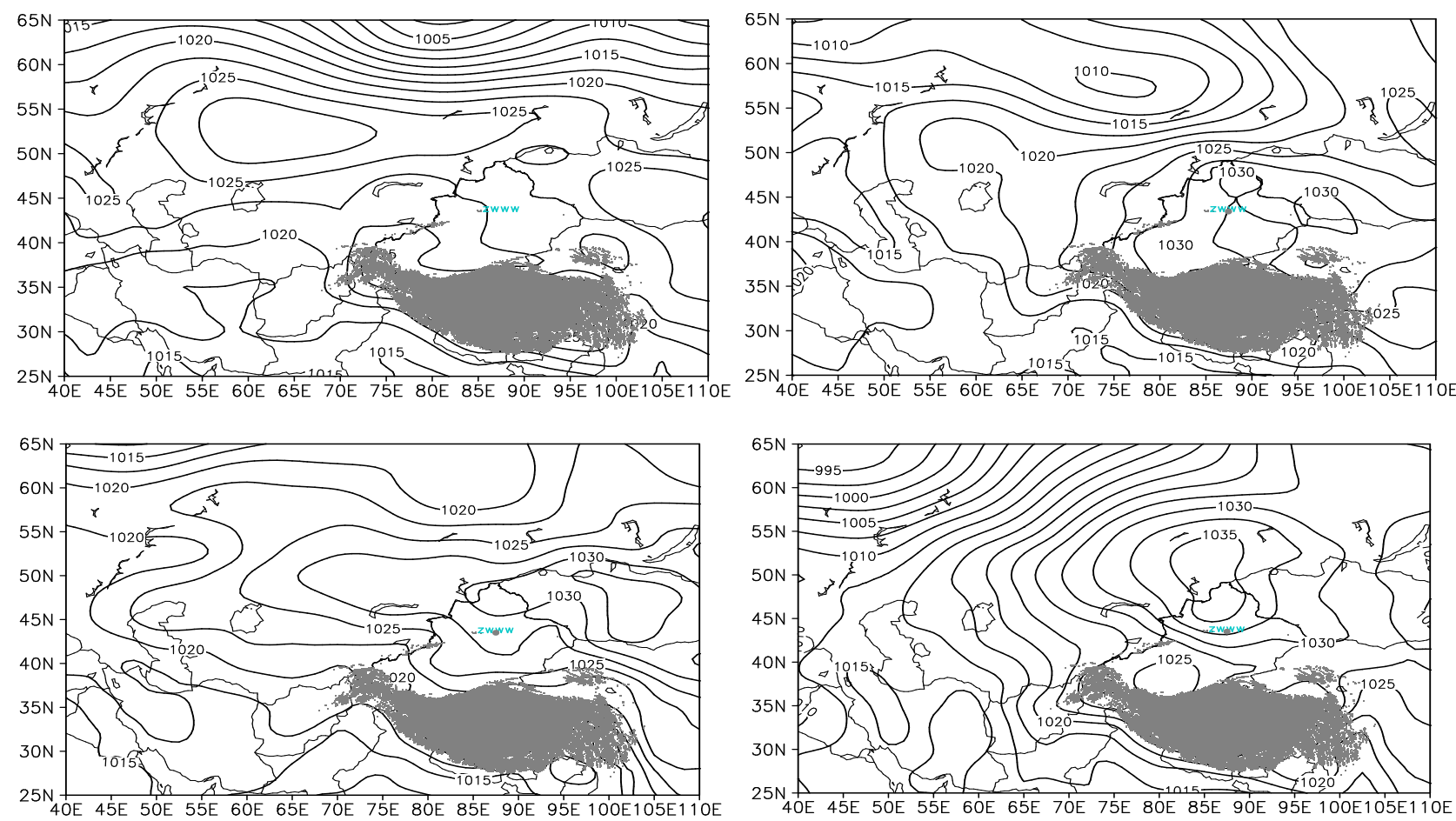

Figure 2. Mean sea level pressure field in the form of freezing fog.

\subsection{Relationship between Visibility and Inversion}

Combined with the existing conclusions [10], the visibility of the field has a good correspondence with the inversion of the T850 and the ground. Therefore, the T850 hpa-T2m is used to characterize the inversion of the sky over the field. The analysis results are as follows.

It can be seen that the visibility of the 2nd and 1st levels is mainly concentrated above 6 degrees (Figure 3). With the increase of the inversion temperature, the weather of the 4 th grade rapidly decreases. The level 3 weather is excessive weather, and the inversion temperature is mainly concentrated at $6-12$ degrees. The calculation method of the score is given in Table 1 . The specific distribution is shown in Table 2.

\subsection{Relationship between Visibility and Relative Humidity of 850 hpa}

For this field, the maintenance of inversion temperature has a great relationship with the wind field of $850 \mathrm{hpa}$. Due to the special topographic effects, in the winter, the dry and warm cover caused by the southeast wind is easy to appear, which makes the 850 hpa dry, and the inversion temperature becomes stronger, and the progress can continue to go down. And in the fine grid data, the accuracy of the wind field and relative humidity of $850 \mathrm{hpa}$ is greater than the ground temperature. In addition, the $850 \mathrm{hpa}$ wind field can also well characterize the occurrence and development of disturbances, so it also has a good indication of the dissipation of heavy fog. So next article will study the relative humidity and 


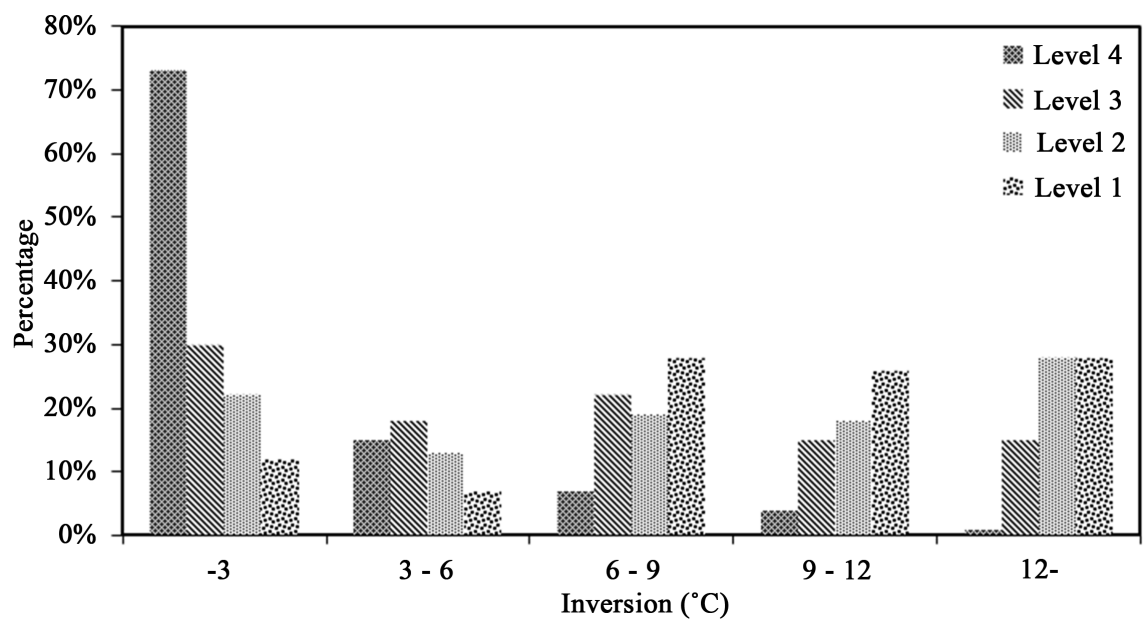

Figure 3. Inverse temperature conditions corresponding to different levels of freezing fog.

Table 2. Distribution of visibility and inversion at different levels.

\begin{tabular}{cccccccccc}
\hline $\begin{array}{c}\text { T850-T2m } \\
\left({ }^{\circ} \mathrm{C}\right)\end{array}$ & Level 4 & Level 3 & Level 2 & Level 1 & $\begin{array}{c}\text { Score } \\
(\text { Lev4) }\end{array}$ & $\begin{array}{c}\text { Score } \\
(\text { Lev 3) }\end{array}$ & $\begin{array}{c}\text { Score } \\
(\text { Lev 2) }\end{array}$ & $\begin{array}{c}\text { Score } \\
(\text { Lev 1) }\end{array}$ & $\begin{array}{c}\text { Total } \\
\text { score }\end{array}$ \\
\hline-3 & $73 \%$ & $30 \%$ & $22 \%$ & $12 \%$ & 0 & 12 & 22 & 60 & 94 \\
$3-6$ & $15 \%$ & $18 \%$ & $13 \%$ & $7 \%$ & 0 & 7 & 13 & 34 & 54 \\
$6-9$ & $7 \%$ & $22 \%$ & $19 \%$ & $28 \%$ & 0 & 9 & 19 & 138 & 166 \\
$9-12$ & $4 \%$ & $15 \%$ & $18 \%$ & $26 \%$ & 0 & 6 & 18 & 131 & 154 \\
$12-$ & $1 \%$ & $15 \%$ & $28 \%$ & $28 \%$ & 0 & 6 & 28 & 138 & 172 \\
\hline
\end{tabular}

wind field of $850 \mathrm{hpa}$.

It can be seen from Figure 4 that the low-visibility weather corresponds to the dry layer development of $850 \mathrm{hpa}$, but the $40 \%-50 \%$ relative humidity period is the over-visible stage, and visibility weather of all levels may occur (Table 3 ).

\subsection{Relationship between Visibility and 850 hpa Wind Field}

A synthetic analysis of the continuous freezing fog weather shows that the wind speed of A $(44,87.5)$ and B $(44,87.25)$ can better characterize the weather system affecting Urumqi Airport. Advancement of the southeast wind layer to the A-B point has an effect on the sky. The disturbance is sensitive at the B-A point when entering the disturbance, and there is a clear northwesterly flow response. Therefore, the paper takes A $(44,87.5)$, B $(44,87.25)$ two points for different levels of visibility, the performance of each wind field is as follows.

It can be seen that the A-point wind field is scattered when it is visible at the 4th level, and the southeast wind $\left(100^{\circ}-180^{\circ}\right)$ also occurs (Figure 5). However, in general, strong winds (greater than $8 \mathrm{~m} / \mathrm{s}$ ) were concentrated in the northwest wind $\left(270^{\circ}-340^{\circ}\right)$, which reflected that cold air entered at that time, and the static structure that formed the frozen fog was broken. As the visibility decreases, the wind direction at point A gradually moves closer to the southeast, and the 


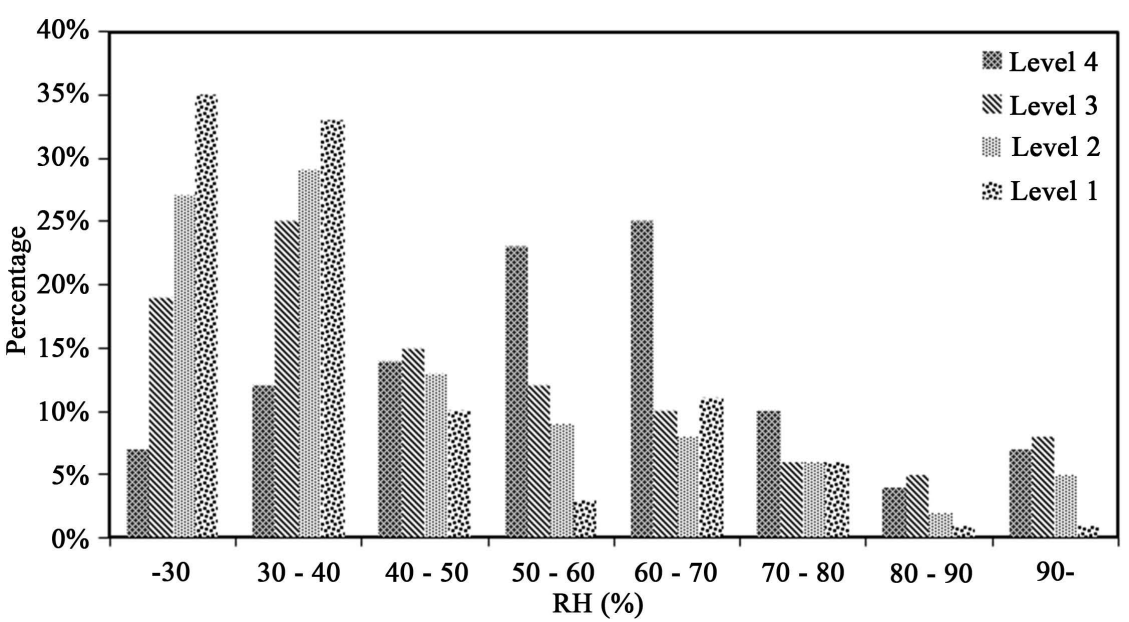

Figure 4. 850 hpa humidity corresponding to different levels of visibility weather.

Table 3. Distribution of visibility and relative humidity at different levels.

\begin{tabular}{cccccccccc}
\hline RH (850 hpa) & Level 4 & Level 3 & Level 2 & Level 1 & $\begin{array}{c}\text { Score } \\
(\text { Lev })\end{array}$ & $\begin{array}{c}\text { Score } \\
(\text { Lev 3) }\end{array}$ & $\begin{array}{c}\text { Score } \\
(\text { Lev 2) }\end{array}$ & $\begin{array}{c}\text { Score } \\
(\text { Lev 1) }\end{array}$ & Score \\
\hline-30 & $7 \%$ & $19 \%$ & $27 \%$ & $35 \%$ & 0 & 7 & 27 & 174 & 208 \\
$30-40$ & $12 \%$ & $25 \%$ & $29 \%$ & $33 \%$ & 0 & 10 & 29 & 167 & 206 \\
$40-50$ & $14 \%$ & $15 \%$ & $13 \%$ & $10 \%$ & 0 & 6 & 13 & 48 & 67 \\
$50-60$ & $23 \%$ & $12 \%$ & $9 \%$ & $3 \%$ & 0 & 5 & 9 & 15 & 29 \\
$60-70$ & $25 \%$ & $10 \%$ & $8 \%$ & $11 \%$ & 0 & 4 & 8 & 56 & 68 \\
$70-80$ & $10 \%$ & $6 \%$ & $6 \%$ & $6 \%$ & 0 & 2 & 6 & 30 & 38 \\
$80-90$ & $4 \%$ & $5 \%$ & $2 \%$ & $1 \%$ & 0 & 2 & 2 & 7 & 11 \\
$90-$ & $7 \%$ & $8 \%$ & $5 \%$ & $1 \%$ & 0 & 3 & 5 & 4 & 12 \\
\hline
\end{tabular}

frequency and wind speed of the southeast wind increase. This feature is also manifested at point B. For point A, the northwesterly wind frequency and wind speed converge faster at point $\mathrm{B}$, and the northwesterly and southeast winds of grades 3, 2 and 1 show greater differences. This is good for the division of visibility.

Combined with the characteristics of $A B$ two-point wind field, this paper only studies the southeast wind $\left(100^{\circ}-200^{\circ}\right)$ and the northwest wind $\left(250^{\circ}-350^{\circ}\right)$. In addition, the establishment of the southeast wind layer contributes to the establishment and maintenance of the inversion layer and the $850 \mathrm{hPa}$ dry layer, so the establishment of the southeast wind has a physical causal relationship with the above extracted indicators. In the field, the occurrence and maintenance of frozen fog has a large proportion, and the southeast wind has a large wind speed, and the freezing fog is thick and long-lasting. The northwest wind speed and visibility are better. Therefore, in the calculation of the following wind direction 
wind speed, the southeast wind speed $(5,10]$ interval, the score is multiplied by 2 , $(10,15]$ interval, and the score is multiplied by 3 on the original basis. The analogy $(20, \infty)$ interval score is multiplied by 5 on the original basis. The specific demarcation scores are as follows.

\begin{tabular}{|c|c|c|c|c|c|c|c|c|c|c|}
\hline $\begin{array}{c}\text { Wind } \\
\text { Direction } \\
\text { of Point A }\end{array}$ & $\begin{array}{l}\text { Wind } \\
\text { Speed }\end{array}$ & Lev 4 & Lev3 & Lev 2 & Lev 1 & $\begin{array}{l}\text { Score } \\
(\operatorname{Lev} 4)\end{array}$ & $\begin{array}{c}\text { Score } \\
(\operatorname{Lev} 3)\end{array}$ & $\begin{array}{c}\text { Score } \\
(\operatorname{Lev} 2)\end{array}$ & $\begin{array}{c}\text { Score } \\
(\operatorname{Lev} 1)\end{array}$ & Score \\
\hline $100-200$ & $00-05$ & $18 \%$ & $34 \%$ & $30 \%$ & $37 \%$ & 0 & 13.5 & 30.4 & 185 & 228.9 \\
\hline $100-200$ & $05-10$ & $7 \%$ & $17 \%$ & $18 \%$ & $19 \%$ & 0 & 6.6 & 17.9 & 190 & 214.5 \\
\hline $100-200$ & $10-15$ & $1 \%$ & $2 \%$ & $2 \%$ & $1 \%$ & 0 & 0.9 & 2.2 & 15 & 18.1 \\
\hline $100-200$ & $15-20$ & $0 \%$ & $0 \%$ & $0 \%$ & $0 \%$ & 0 & 0 & 0 & 0 & 0 \\
\hline $100-200$ & $20-$ & $0 \%$ & $0 \%$ & $0 \%$ & $0 \%$ & 0 & 0 & 0 & 0 & 0 \\
\hline $250-350$ & $00-05$ & $21 \%$ & $18 \%$ & $21 \%$ & $13 \%$ & 0 & 7.4 & 20.9 & 63.4 & 91.7 \\
\hline $250-350$ & $05-10$ & $22 \%$ & $11 \%$ & $7 \%$ & $4 \%$ & 0 & 4.3 & 6.6 & 22.4 & 33.3 \\
\hline $250-350$ & $10-15$ & $2 \%$ & $1 \%$ & $0 \%$ & $0 \%$ & 0 & 0.4 & 0.4 & 0 & 0.8 \\
\hline $250-350$ & $15-20$ & $0 \%$ & $0 \%$ & $0 \%$ & $0 \%$ & 0 & 0 & 0.4 & 0 & 0.4 \\
\hline $250-350$ & $20-$ & $0 \%$ & $0 \%$ & $0 \%$ & $0 \%$ & 0 & 0 & 0 & 0 & 0 \\
\hline $\begin{array}{c}\text { Wind } \\
\text { Direction } \\
\text { of Point B }\end{array}$ & $\begin{array}{l}\text { Wind } \\
\text { Speed }\end{array}$ & Lev 4 & Lev3 & Lev 2 & Lev 1 & $\begin{array}{l}\text { Score } \\
(\operatorname{Lev} 4)\end{array}$ & $\begin{array}{c}\text { Score } \\
(\operatorname{Lev} 3)\end{array}$ & $\begin{array}{c}\text { Score } \\
(\operatorname{Lev} 2)\end{array}$ & $\begin{array}{c}\text { Score } \\
(\operatorname{Lev} 1)\end{array}$ & Score \\
\hline $100-200$ & $00-05$ & $15 \%$ & $17 \%$ & $11 \%$ & $19 \%$ & 0 & 6.7 & 11.4 & 95 & 113.1 \\
\hline $100-200$ & $05-10$ & $7 \%$ & $25 \%$ & $23 \%$ & $30 \%$ & 0 & 9.9 & 23.1 & 300 & 333 \\
\hline $100-200$ & $10-15$ & $3 \%$ & $9 \%$ & $15 \%$ & $10 \%$ & 0 & 3.4 & 15.0 & 150 & 168.4 \\
\hline $100-200$ & $15-20$ & $1 \%$ & $2 \%$ & $3 \%$ & $5 \%$ & 0 & 1.0 & 3.3 & 100 & 104.3 \\
\hline $100-200$ & $20-$ & $0 \%$ & $1 \%$ & $1 \%$ & $3 \%$ & 0 & 0.5 & 0.7 & 75 & 76.2 \\
\hline $250-350$ & $00-05$ & $22 \%$ & $18 \%$ & $23 \%$ & $11 \%$ & 0 & 7.3 & 22.7 & 56 & 86 \\
\hline $250-350$ & $05-10$ & $22 \%$ & $11 \%$ & $7 \%$ & $6 \%$ & 0 & 4.5 & 7.0 & 29.9 & 41.4 \\
\hline $250-350$ & $10-15$ & $4 \%$ & $1 \%$ & $1 \%$ & $0 \%$ & 0 & 0.5 & 1.1 & 0 & 1.6 \\
\hline $250-350$ & $15-20$ & $1 \%$ & $0 \%$ & $0 \%$ & $0 \%$ & 0 & 0.0 & 0.4 & 0 & 0.4 \\
\hline $250-350$ & $20-$ & $0 \%$ & $0 \%$ & $0 \%$ & $0 \%$ & 0 & 0.0 & 0.0 & 0 & 0 \\
\hline
\end{tabular}

The wind fields of other times are replaced by the average value of the point. Finally, the data and the current wind field value are calculated by two points of AB. 

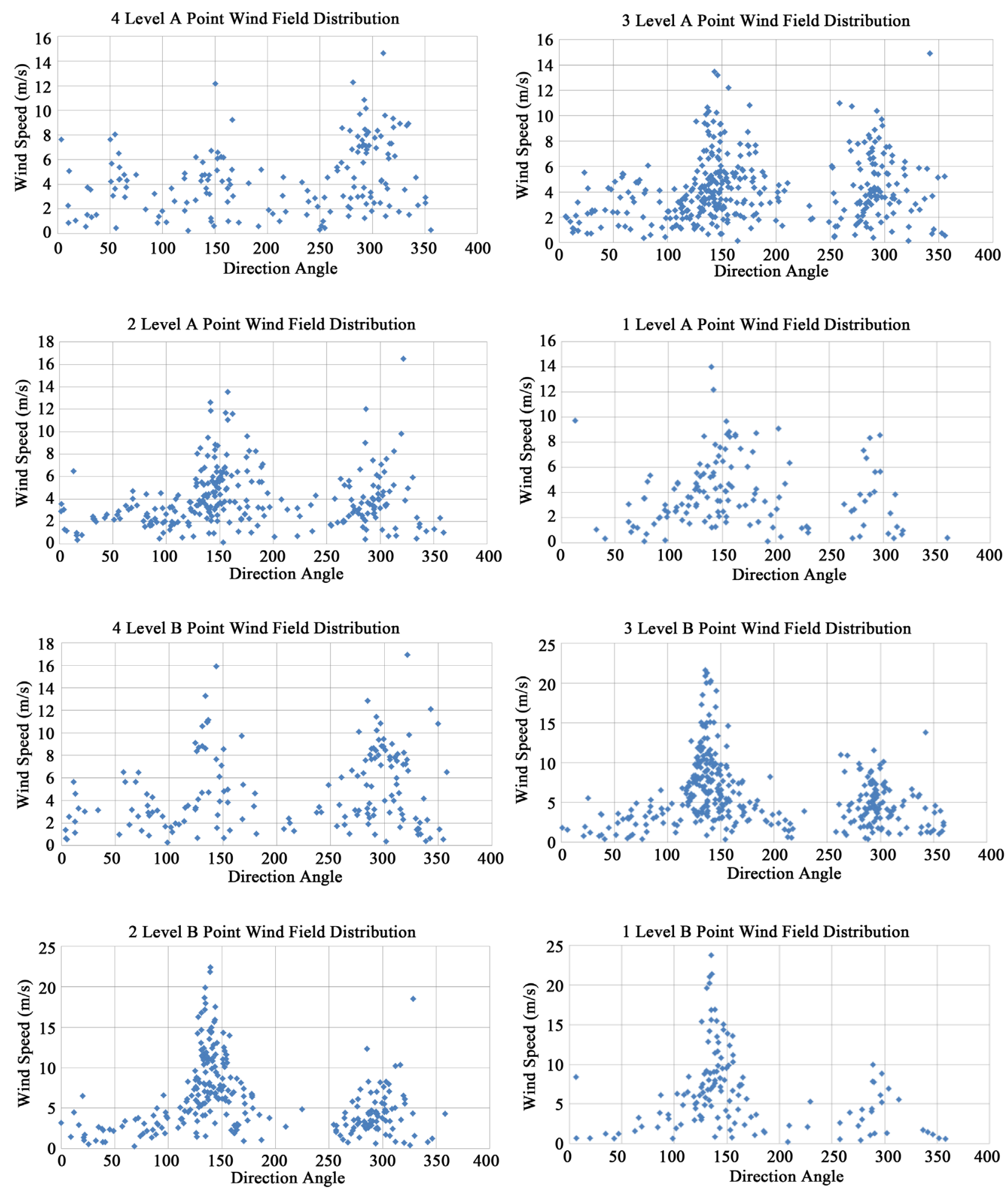

Figure 5. $8 \mathrm{AB}$ two points correspond to different levels of wind field distribution.

\section{Visibility Level}

According to the above analysis of physical quantity standards, this paper compares the time values with the visibility, and the results are as follows: 
It can be seen that $84.2 \%$ level 4 is concentrated below 400 points, followed by a significant downward trend. Level 1 is the opposite, $63 \%$ is concentrated above 1000 points, and each level is less distributed at 600 - 1000 points. According to Figure 6, the level 2 level 3 resolution is not good, but level 1 and level 4 have significant differences. This has a good indication of daily work. Level 1 corresponds to a visibility of less than 500 meters, which does not meet the flight operating standards, and in most cases, the corresponding RVR is also below the operating standard. The visibility corresponding to level 4 is greater than 3000 meters. Above the operating standard, the aircraft can operate normally. Therefore, the definition score $\leq 400$ is judged as level $4, \geq 1000$ points is judged as level 1 , and the remaining scores are level 2 and level 3. The above two levels are not differentiated because they are all above the operational standards and most of the time does not affect the operation, but it is still closely monitored.

\section{Inspection Result}

Apply the data from December 2016 to February 2017 for the test and calculate according to the above method. Here we only check the forecast accuracy of level 1 and level 4. The accuracy rate of level 1 is $61.2 \%$, and that of level 2 is $68.2 \%$, which has certain indication significance in actual work; and the accuracy rate of level 4 is $97.2 \%$, and the forecast is good.

\section{Conclusions}

1) It is feasible to use the European fine mesh $500 \mathrm{hpa}$ height field/temperature field, 850 hpa relative humidity, 850 hpa wind field, 850 hpa temperature, T2m temperature, average sea level pressure and other physical quantities to test the visibility of the field, and it has certain warning effect.

2) The forecast of fog needs to be combined with the advancement and the correction. The method of this paper can predict the fog. The prediction of

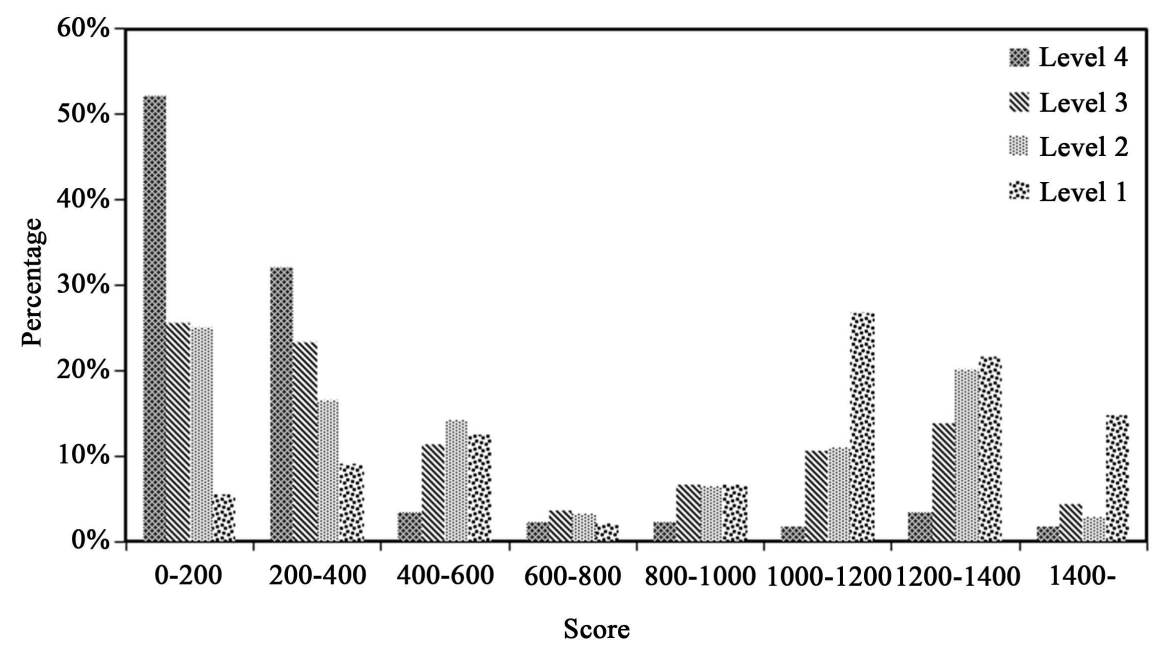

Figure 6. Corresponding situation of different levels of visibility judgment values. 
visibility is based on the upstream and downstream effects, the wind profile and the performance of the surface wind field humidity.

3) The accuracy of this method for fog forecasting below 500 meters is $61.2 \%$, and the accuracy of fog forecasting above 3000 meters is $97.2 \%$. The conclusion is good and it has guiding significance for actual forecasting.

\section{Conflicts of Interest}

The authors declare no conflicts of interest regarding the publication of this paper.

\section{References}

[1] Civil Aviation Administration of China (2013) 2012 Civil Aviation Industry Development Statistics Bulletin.

[2] Liang, A.M., Zhang, Q.H., Shen, H.X., Liu, K.Y., Li, X.L. and Feng, J.B. (2009) Analysis and Numerical Simulation of an Advection Fog Process in Beijing Area. Applied Meteorological Journal, 20, 612-621.

[3] Lin, Y., Wang, M.S. and Lin, L.G. (2013) Numerical Simulation of Winter Mist and Parameterization of Visibility in Sichuan Province. Journal of NUIST (Natural Science Edition), 5, 222-228.

[4] Lai, X.F. (2010) Numerical Simulation Analysis of an Advection Fog in Shanghai Pudong Airport. Zhejiang Meteorological Society, Shanghai Meteorological Society, Jiangsu Meteorological Society, The 7 th Yangtze River Delta Meteorological Science and Technology Forum Proceedings, 7.

[5] Zhu, L. (1999) Low-Visibility Weather and Climate Characteristics of Urumqi Airport. Hubei Weather, 4, 8-10.

[6] Wang, N., Yang, H.R. and Liang, Y. (2015) Analysis of the Characteristics of Fog Heterogeneity in Urumqi Airport in the Past 37 Years. Desert and Oasis Weather, 4 , 43-49.

[7] Yang, H.R., Wang, N. and Li, X. (2014) The Characteristics of the Fog in Urumqi Airport in Recent 36 Years and the Classification of Weather Conditions. The 31 st China Meteorological Society Annual Meeting S10, The 4th Meteorological Service Development Forum to Improve the Level of Hydrometeorological Disaster Prevention and Mitigation, and Promote the Social Development of Meteorological Services, Public Meteorological Services Committee, Hydrometeorological Committee, Public Weather Service Center of China Meteorological Administration, Hydrology Bureau of Ministry of Water Resources, 15.

[8] Wei, T.T., Zheng, L. and Gong, X.W. (2015) An Objective Forecasting Method for Significant Precipitation Based on T639 Physical Quantity Products. Meteorological Disaster Prevention, 22, 18-21.

[9] Wang, N., Zhu, L., Yang, H., et al. (2017) Classification of Synoptic Circulation Patterns for Fog in the Urumqi Airport. Atmospheric \& Climate Sciences, 7, 352-366. https://doi.org/10.4236/acs.2017.73026

[10] Wang, N. and Yang, H.R. (2016) Analysis on Characteristics of Heavy Fog Change in Different Time Period of Urumqi Airport. Civil Aviation in China, Supp, 35-37. 